\title{
O PACIENTE DE UNIDADE DE TERAPIA INTENSIVA E A PERCEPÇÃO DOS CUIDADOS DE HIGIENE CORPORAL*
}

\author{
Cilene Aparecida Costardi Ide**
}

IDE, C.A.C. O paciente de unidade de terapia intensiva e a percepcáo dos cuidados de higiene corporal. Rev. Esc. Enf. USP, Sao Paulo, 22(2):151-157, ago. 1988.

Neste estudo foram analisados aspectos relacionados à maneira como pacientes criticos percebem. vivenciam e avaliam o atendimento d necessidade de higiene corporal enquanto internados numa Unidade de Terapia Intensiva (UTI).

UNITERMOS: Unidade de Terapia Intensiva. Higiene corporal. Assistência de enfermagem.

\section{INTRODUÇÃO}

Este trabalho teve como objeto de investigação o paciente critico, sujeito à dinâmica da Unidade de Terapia Intensiva (UTI), com a integridade física comprometida pelos diferentes artefatos terapêuticos, e sua percepção sobre a necessidade e a prática dos cuidados de higiene corporal.

Representou, antes de mais nada, a crença na validade da assistência intensiva, bem como a certeza, embasada em alguns anos de vivência, de que, graças à dedicação de uma equipe que convive continuamente com a vida e a morte, e com o estresse físico e emocional, muitos doentes, apesar de todo o sofrimento decorrente do tratamento, tiveram mais do que a saúde recuperada e a vida mantida.

Por outro lado, representa, também, um momento de reflexão sobre se a preocupação com todo arsenal tecnológico caracteristico de uma UTl e o exercicio das atividades administrativas ou das médico-delegadas estarão afastando a enfermeira da assistência direta ao paciente critico, fazendo-a relegar toda oportunidade de contato e interação com o doente, inerente à prestação de cuidados corporais, principalmente ao atendimento da necessidade de higiene corporal, atividade de sua total responsabilidade. Na medida em que esta é relegada a segundo plano, inúmerose constantes agravos à integridade e bem estar dos doentes podem ocorrer, quer por omissăo quer por inadequação qualitativa ou quantitativa desses cuidados.

Tal atitude da profissional pode determinar modificaçðes no hábito de higiene corporal do paciente crítico, possivelmente devidas a três fatores.

O primeiro deles decorre do paciente depender totalmente da equipe de enfermagem para a satisfação dessa necessidade; sua situação de acamado é agravada pelo comprometimento físico consequiente tanto da debilidade física quanto da presença dos diferentes procedimentos invasivos no tratamento intensivo.

- Resumo da Dissertaça de Mestrado apresentada à Escola de Enfermagem da USP, 1984.

- Enfermeira. Mestre em Enfermagem. Professora Assistente do Departamento de Enfermagem Médico-Cirúrgica da Escola de Enfermagem da USP - disciplina Enfermagem Médico-Cirürgica. 
Outro fator a influenciar os hábitos higiênicos desse indivíduo relaciona-se à execução e avaliação da assistência; na prática, predomina uma atitude dominadora da equipe, que estabelece horário, rítmo e freqüência desses cuidados, limitando, assim a possibilidade do próprio paciente executar as atividades que queira, saiba e possa fazer.

O terceiro fator a ser considerado refere-se à percepção desse atendimento pelo paciente crítico, ou seja, à maneira como ele sente e vivencia a necessidade e a prática de tais cuidados na UTI.

A partir dessas consideraçðes, fomos motivadas a conhecer como uma pessoa gravemente enferma, repentinamente admitida a uma unidade desconhecida e fecha$\mathrm{da}$, com a sua integridade física comprometida pela presença de drenos, sondas, artefatos e aparelhos desconhecidos, se sente sendo assistida por estranhos; qual o significado, para esse doente, de se tornar dependente, de ter a sua intimidade violada num ambiente pouco privativo, de ter os seus hábitos higiênicos modificados segundo as rotinas e a dinâmica da UTI.

O presente estudo teve, portanto, como objetivos:

- detectar a percepção do paciente de UTI quanto aos cuidados de higiene corporal prestados pela equipe de enfermagem;

- identificar possivel associação entre a percepção do paciente de UTl quanto aos cuidados de higiene corporal e as variáveis sexo, idade e nivel quantitativo de procedimentos invasivos inerentes ao seu tratamento.

\section{METODOLOGIA}

Foram selecionados 45 pacientes adultos, de ambos os sexos, que permaneceram conscientes, internados na UTI pelo menos por 36 horas e que, após a alta dessa unidade, ainda continuaram hospitalizados. Tais doentes foram entrevistados, apos consentimento, no segundo dia de permanência na unidade de internação.

\section{RESULTADOS E COMENTÁRIOS}

\section{Caracterização da população}

Os resultados obtidos retrataram uma população com predominância masculina $(64,4 \%)$, numa faixa etária relativamente elevada, pois $84,5 \%$ tinham mais de 50 anos. O nivel de instrução predominantemente foi baixo, com a maioria tendo cursado somente o primário. Quanto à forma de pagamento houve equilibrio, pois $51,0 \%$ do grupo foi constituido por pacientes particulares e os outros $49,0 \%$ por conveniados, incluindo os dependentes do INAMPS.

Detectou-se, também, predominância dos pacientes admitidos para tratamento clínico $(62,2 \%)$ sobre os cirúrgicos. Vale acrescentar que o primeiro grupo foi constituido basicamente de portadores de afecções cardiacas e o segundo, de doentes em pós-operatório de cirurgias abdominais e vasculares.

A análise comparativa entre os tipos de tratamento e os procedimentos invasivos utilizados, possibilita a constatação de que, qualitativamente, os diferentes procedimentos (incisão, punção, dreno, sonda, catéter e aparelho) estão presentes em ambos os grupos, diferindo, contudo, quanto à freqüência. As diferenças quantitati- 
vas detectadas coincidem com a suposição de que as condutas utilizadas nos pacientes clinicos são menos invasivas, limitando-se, predominantemente, a punções percutâneas $(53,3 \%)$ e ao uso de aparelhos $(51,1 \%)$. Entre os pacientes cirúrgicos foi expressivamente maior a presença de outros procedimentos tais como: incisðes, em todos eles, assim como a utilização de sonda $(35,6 \%)$.

Contudo, a agressão física foi constante em todos, pois foi de 4 a média, o modo e a mediana dos procedimentos invasivos a que foi submetido cada paciente.

Constatou-se, ainda, que tanto os pacientes clinicos quanto os cirúrgicos, independentemente do tipo de tratamento e do número de procedimentos invasivos utilizados, tiveram uma permanência curta na UTI; 36(80,2\%) deles ficaram menos de 4 dias nessa unidade.

\section{Percepção dos cuidados de higiene corporal}

Os resultados obtidos evidenciaram que dos cuidados higiênicos a serem ministrados ao paciente crítico, somente o banho no leito foi expressivamente relatado, sendo significativa a informação de queixas quanto à falta de outros cuidados, refe-

TABELA 1

PACIENTES SEGUNDO A REFERENCIA E OS TIPOS DE CUIDADOS DE HIGIENE CORPORAL CITADOS. SAOO PAULO, 1983

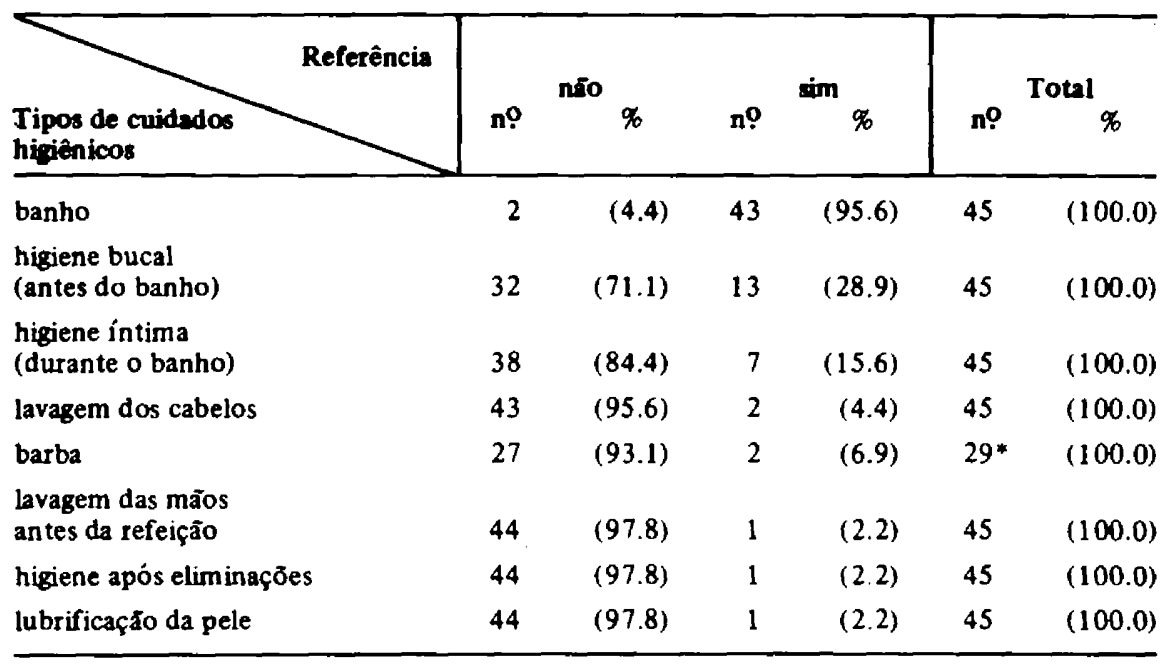

- populaçăo masculina.

ridas por $\mathbf{2 4 , 5 \%}$ dos doentes, assim distribuidas: ausência de banho (2); higiene oral (6); lavagem dos cabelos e higiene intima (2).

Complementando esses dados, é necessário esclarecer que apenas 1 paciente foi previamente consultado quanto aos cuidados que gostaria de receber. Do contingente total de doentes, $27(62,8 \%)$ referiram terem participado dos próprios cuidados higiênicos, com 25 referências de auxílio na movimentação e 6 de auto execução de higiene oral ou intima. 
Vale ainda salientar que, apesar do único cuidado expressivamente citado ter sido o banho, de 11 pacientes terem sentido falta de atendimento e destes, 8 não os terem solicitado por medo de incomodar ou de năo ser atendido, a maioria considerou satisfatório e suficiente o atendimento recebido (respectivamente $83,7 \%$ e $86,0 \%$ ).

Em contrapartida, os comentários manifestos retratam o predomínio de atitude de crítica aos cuidados de higiene corporal prestados.

\section{TABELA 2}

\section{PACIENTES SEGUNDO OS COMENTÁRIOS REFERENTES AOS CUIDADOS DE HIGIENE CORPORAL. SAO PAULO, 1983.}

\begin{tabular}{lcc}
\hline Comentários & n9 & $\%$ \\
\hline de queixas & 19 & $(44,2)$ \\
de satisfação & 15 & $(34,9)$ \\
não comentaram & 9 & $(20,9)$ \\
\hline TOTAL & 43 & $(100,0)$ \\
\hline
\end{tabular}

As queixas expressas por $19(44,2 \%)$ doentes referiam-se principalmente: ao fato de terem sido cuidados por pessoas do sexo oposto; à falta de cuidados; à pouca privacidade; ao desconforto, além do barulho, conversas e brincadeiras presentes durante a prestação da assistência.

Os comentários dos $15(34,9 \%)$ pacientes que justificaram a satisfação caracterizarám uma atitude de aceitação e/ou agradecimento referindo "terem se sentido amparados", ou porque "o que fizerem está bom".

Vale ainda salientar que um número expressivo de 9 doentes $(20,9 \%)$ optou por não tecer quaisquer comentários a respeito.

Constatou-se, ainda, que vergonha, dor e desconforto foram as sensações mais experimentadas durante esse atendimento de enfermagem.

TABELA 3

REFERENCIA DE SENSAÇOOES EXPERIMENTADAS DURANTE A PRESTAÇÃO DOS CUIDADOS DE HIGIENE CORPORAL. SÃO PAULO, 1983.

\begin{tabular}{lcc}
\hline Sensaçōes & $\mathbf{n}$ ? & $\%$ \\
\hline vergonha & 23 & $(35,9)$ \\
dor & 14 & $(21,9)$ \\
desconforto & 11 & $(17,2)$ \\
medo & 10 & $(15,6)$ \\
insegurança & 6 & $(9,4)$ \\
\hline TOTAL & 64 & $(100,0)$ \\
\hline
\end{tabular}


Complementando essa informação, deve-se acrescentar que a referência da vergonha pela exposição física foi feita principalmente por mulheres, pacientes mais idosos e aqueles com menor número de procedimentos invasivos.

Pode-se também verificar que não houve associação estatisticamente significanle entre as variáveis sexo, idade, nível quantitativo de procedimentos invasivos e percup̣cào quanto à particinação e referência de falta dos cuidados higiênicos.

\section{CONSIDERAÇÕES FINAIS}

Ser assistido em UTl pode significar, para a maioria dos pacientes, uma rutura e ameaça a um projeto existencial, fazendo emergir a sua vulnerabilidade perante a morte e a sua dependência de outrem, o que pode gerar sentimentos peculiares e modificaçð̃es, inclusive nos hábitos de higiene corporal.

Nesse sentido, era esperada grande preocupação da enfermeira da UTI sobre as condições higiênicas desse indivíduo, altamente comprometidas, não somente pela situaçăo de acamado e dependente, como também pela adição dos artefatos terapêuticos inerentes ao tratamento intensivo, todos eles fatores potenciais de dor, infecção, desconforto e limitação de movimentos. Essa preocupação deveria refletir-se, também, na investigação dos hábitos dos pacientes, fontes primordiais de informaçð̌s para subsidiar a assistência planejada e executada para eles, que, dessa maneira, facultaria comunicação efetiva enfermeiro-paciente, propulsora da participação no auto-cuidado. Verificou-se, porém, que essa expectativa não foi confirmada.

Os resultados encontrados evidenciaram que os cuidados higiênicos referidos limitaram-se para a maioria dos pacientes, independentemente dos fatores idade, sexo e condiçðes físicas, quase exclusivamente ao banho, antecedido de higiene bucal, conforme a rotina dessa unidade.

Outro dado que despertou preocupação foi a constatação de que apenas um paciente foi previamente consultado sobre quais cuidados gostaria de receber. Tal fato parece ter evidenciado a não individualização desses cuidados, o que pressupōe a existência de rotinas pré-estabelecidas nas quais todos parecem ter sido enquadrados.

Todas as percepçòes referidas pela população retrataram um atendimento limitado e impessoal o que caracteriza determinada atitude, tanto da equipe quanto do paciente. Por parte do doente, a aceitaçào e satisfação para com a assistência recebida poderiam decorrer da perplexidade, comum a todos, causada pela doença e pela permanência na UTI; da debilidade física e psíquica inerente a sua condição, da aceitação passiva de dependência, das rotinas estabelecidas pela equipe de enfermagem para atender à necessidade de higiene corporal ou, talvez, porque o desejo de sobreviver extrapole essa dimensão da assistência.

Contudo, esse perfil de atendimento aliado às reclamações quanto à vergonha da nudez, assim como de ser cuidado por pessoas do sexo oposto, além dos referentes à pouca privaticidade proporcionada pela equipe de enfermagem, caracterizaram uma triste realidade para qual os enfermeiros devem ser alertados.

Tem-se a impressão de que o ser humano, por estar doente, ficou reduzido a alguem sem sentimentos, sem pudor, sem o direito inalienável de ter a sua individualidade $e$ intimidade respeitadas. É como se mantê-lo vivo, justificasse todo o desrespeito manifesto nessas queixas.

Em sintese, os achados do presente trabalho conduzem a profunda reflexão so- 
bre a prática da enfermaseın na UTI, como um todo, em seus aspectos assistenciais, docentes e de investigaçảo.

O enfermeiro deve reconhecer que assistir a um paciente crítico é muito mais do que manter-lhe a vida, controlar parâmetros hemodinâmicos, manipular eficientemente aparelhos, limpar o seu corpo ou administrar medicação. É primordialmente ampará-lo, respeitá-lo, garantir-lhe a participação ativa no próprio processo de recuperação, prestar-lhe a assistência individualizada que ele merece e deseja; enfim, demonstrar a humanidade na prática da Enfermagem.

Por outro lado, se a prática é a projeçāo da formação, somente um processo ensino-aprendizagem coerente e crítico poderá gerar um profissional forte, que nāo se esconde e nem assume, mecanicamente, rotinas ultrapassadas. Um enfermeiro, formado dentro deste contexto, não se deixará sucumbir ante o peso burocrático da instituição, que muitas vezes induz e cobra uma prestação de assistência impessoal, somatória de tarefas estanques, e nem será absorvido pelas atividades tecnicistas da UTI. Saberá, antes de mais nada, fundamentar e priorizar a próprịa prática, assumindo definitivamente o compromisso não só com a manutençăo da vida, como também com a qualidade dessa vivência, isto é, com o bem estar do paciente de UTI, valorizando a oportunidade de contacto e relacionamento que a execução dos cuidados corporais possibilita. A esse profissional caberá, também, a luta por condições de trabalho que viabilizem uma assistência aprimorada, qualitativa e quantitativamente, que garantam os direitos dos pacientes e proporcionem à equipe de saúde a possibilidade de desempenho compativel com essas expectativas.

\section{CONCLUSÕES}

Os resultados da pesquisa realizada junto a 45 pacientes que estiveram internados na UTI, para investigação da percepção dos cuidados de higiene corporal, conduziram às conclusòes que seguem:

- A maioria da população $(95,6 \%)$ recordou ter recebido, como cuidado higiênico, durante a permanência nessa unidade, o banho no leito. Desse total, 13(28,9\%) doentes referiram terem recebido a higiene bucal antecendo o banho e $7(15,6 \%)$ a higiene intima durante esse atendimento.

- Um contingente de $34(75,5 \%$ ) pacientes informou não ter sentido falta de cuidados higiênicos, em contraposição aos $11(24,5 \%)$ que expressaram diferentes carências referentes a essé atendimento de enfermagem.

- Apenas $1(2,2 \%)$ paciente foi consultado sobre os cuidados higiênicos que gostaria de receber, como subsidio para o planejamento desse atendimento.

- A participação na execução dos próprios cuidados higiênicos foi referida por $27(62,8 \%)$ dos doentes, que se limitaram, predominantemente, a auxiliar na movimentaçào.

- Vergonha $(35,9 \%)$, dor $(21,9 \%)$ e desconforto $(17,2 \%)$ foram as sensaçòes mais citadas por $35(81,4 \%)$ pacientes que informaram ter experimentado sensaçòes durante a prestação desses cuidados.

- Os cuidados de higiene corporal foram considerados satisfatórios por $36(83,7 \%)$ doentes e suficientes por $37(86,0 \%)$ deles.

- Do total de 43 pacientes que referiram ter recebido cuidados higiênicos na UTI, $19(44,2 \%)$ expressaram as seguintes queixas quanto ao atendimento recebido: 
vergonha causada pela exposição física durante a execução dos cuidados higiênicos ou por ser cuidado por pessoas do sexo oposto; falta de cuidados; pouca privacidade, barulho, conversa ou brincadeiras, além do desconforto durante a prestação desses cuidados pelo pessoal da enfermagem.

Pode-se, também, concluir que não houve associação estatísticamente significante entre as variáveis sexo, idade e nivel quantitativo de procedimentos invasivos e a percepção, no que se refere à participação do paciente no auto cuidado, assim como à referência de falta de cuidados.

Constatou-se, ainda, que as mulheres, os mais idosos e os pacientes com menor número de procedimentos invasivos foram os que mais informaram ter sentido vergonha durante esse atendimento de enfermagem.

IDE, C.A.C. The intensive care unit patient and the perception to corporal hygienic care. Rev. Esc.

Enf. USP, Sào Paulo, 22(2):151-157, Aug. 1988.

This report analised the view of critical patients about the necessity and practice of corporal hygienic care in an intensive care unit.

UNITERMS: Intensive care units. Body hygiene. Nursing care.

Recebido para publicaçăo em 03/02/87.

Aprovado para publicação em junho de 1988. 